\title{
As parcerias público-privadas: reflexões sobre o conceito de hegemonia no contexto das políticas educacionais municipais
}

\author{
Public-private partnerships: reflections on the concept of hegemony \\ in the context of municipal educational policies
}

\begin{abstract}
Asociaciones pública-privadas: reflexiones sobre el concepto de hegemonía en el contexto de las políticas educacionales municipales
\end{abstract}

\author{
Kelly Letícia da Silua Sakata ${ }^{1}$ \\ Universidade Estadual do Centro-Oeste, Professora colaboradora. \\ https://orcid.org/0000-0003-4176-0412 \\ Michelle Fernandes Lima² \\ Universidade Estadual do Centro-Oeste, Professora. \\ https://orcid.org/0000-0003-0896-4747
}

Resumo: 0 presente texto objetiva refletir sobre a categoria hegemonia em Antônio Gramsci (18911937) no que concerne às parcerias público-privadas estabelecidas entre a esfera administrativa educacional municipal e as Fundações privadas e Associações sem fins lucrativos (Fasfil). Para tanto, analisa, a partir de uma perspectiva histórica, a emergência das parcerias público-privadas na esfera administrativa municipal, principalmente a partir de 1990. Ainda, com base nos dados disponíveis no Catálogo de Teses e Dissertações da CAPES (2018), indica as pesquisas que discorrem sobre as parcerias público-privadas no contexto municipal e, por fim, problematiza a atuação da classe subalterna no fomento de outra hegemonia.

Palavras-chave: Hegemonia. Parcerias público-privadas. Políticas educacionais.

Abstract: This text has as aim to reflect on the category hegemony by Antônio Gramsci (1891-1937), regarding the public-private partnerships established between the educational municipal administrative scope and the private foundations and Non-Profit Associations (Fasfill in its Portuguese acronym. Thereunto, it analyzes from a historical perspective, the emergence of public-private partnerships in municipal administrative scope, especially from 1990. Based on data available in the Catálogo de Teses e Dissertações da CAPES (2018), still indicates the researches that deal on public-private partnerships

Mestre em Educação pela Universidade Estadual do Centro-Oeste; doutoranda pela Universidade Federal do Paraná.

Pós-doutora pela Universidade Estadual de Ponta Grossa; Doutora em Educação pelo Programa de Pós Graduação em Educação da Universidade Federal do Paraná. 
in the municipal context, and finally problematizes the subaltern class actions on another hegemony development.

Keywords: Hegemony. Public-private partnerships. Educacional policies.

Resumen: El texto tiene el objetivo de reflejar sobre la categoría hegemonía en António Gramsci (18911937), en lo que se refiere a las asociaciones público-privadas establecidas entre el ámbito administrativo educacional municipal y las Fundaciones privadas y Asociaciones sin fines lucrativos (Fasfil). Para ello, analiza, desde una perspectiva histórica, la emergencia de las asociaciones público-privadas en el ámbito administrativo municipal, principalmente desde 1990. Basado en los datos disponibles en el Catálogo de Tesis y Disertaciones de la CAPES (2018), aún indica las investigaciones que discurren sobre las asociaciones público-privadas en el contexto municipal, y por fin problematiza la actuación de la clase subalterna en la promoción de otra hegemonía.

Palabras clave: Hegemonía. Asociaciones público-privadas. Políticas educacionales.

Recebido em 3 de julho de 2019

Aceito em 25 de novembro 2019

Publicado em 22 de julho de 2020

\section{INTRODUÇÃO}

Propomos, no presente texto, refletir sobre o conceito de hegemonia no contexto das políticas educacionais municipais, especificamente no que concerne às parcerias públicoprivadas (PPP) entre as secretarias educacionais municipais e as Fundações privadas e Associações sem fins lucrativos (Fasfil). Nesta direção, problematizamos: como o conceito de hegemonia em Antônio Gramsci ${ }^{3}$ pode ajudar no entendimento da emergência das PPP na esfera administrativa municipal e na atuação da classe subalterna nesse contexto?

Essa problematização foi delineando-se no desenvolvimento da pesquisa de Dissertação intitulada Programa gestão para aprendizagem: a atuação da Fundação Lemann nas políticas de formação em Redes Municipais de Educação. Assim como a partir de estudos que foram realizados no âmbito do Programa de Pós-Graduação em Educação da Universidade Estadual de Ponta Grossa (UEPG), na disciplina nomeada Tópicos especiais: Estado e Educação em Antônio Gramsci. Nesse âmbito estudamos, entre outras, a categoria hegemonia em Gramsci. 
Indicamos que nossa perspectiva epistemológica é de cunho marxista, a qual possui um compromisso de transformação da realidade, ou seja, apontamos que "[...] não é a crítica, mas a revolução a força motriz da história e também da religião, da filosofia e de toda forma de teoria." (MARX; ENGELS, 2007, p. 43). Compreendendo as dificuldades de interpretação 4 que os escritos de Gramsci apresentam, sinalizamos que se trata de reflexões iniciais.

A palavra hegemonia, etimologicamente, vem do grego hegemonía, que significa comando. No dicionário é um substantivo feminino que indica supremacia entre cidades, nações ou povos (DICIONÁRIO PRIBERAM, [20--?̣]). Em Gramsci, a categoria hegemonia significa a capacidade dirigente que uma classe social exerce na sociedade, não apenas como direção política, mas também como direção moral, cultural e ideológica. Gramsci emprestou esse termo de Lênin, que o utilizou em 1905 (GRUPPI, 1978, 1986; SHEEN, 2007).

Nesse sentido, a capacidade da classe dirigente caracteriza-se "[...] pela combinação da força e do consenso, que se equilibram de modo variado, sem que a força suplante em muito o consenso, mas, ao contrário, tentando fazer com que a força pareça apoiada no consenso da maioria." (GRAMSCl, 2016, p. 96). Para entendermos a relação da força e do consenso em Gramsci, indicamos que ela ocorre por intermédio do Estado, em que, ainda para Gramsci, está além de um ordenamento social, caracterizando-se pela junção da sociedade civil mais sociedade política. Dito de outro modo,

\footnotetext{
[...] podem-se fixar dois grandes "planos" superestruturais: o que pode ser chamado de "sociedade civil" (isto é, o conjunto de organismos designados vulgarmente como "privados") e o da "sociedade política ou Estado", planos que correspondem, respectivamente, à função de "hegemonia" que o grupo dominante exerce em toda a sociedade e àquela de "domínio direto" ou de comando, que se expressa no Estado e no governo "jurídico". Estas funções são precisamente organizativas e conectivas. (GRAMSCl, 2001, p, 20-21, grifo do autor).
}

Assim, o Estado "[...] tem e pede o consenso, mas também 'educa' este consenso através das associações políticas e sindicais, que, porém, são organismos privados, deixados à iniciativa privada da classe dirigente." (GRAMSCl, 2016, p. १२1, grifo do autor). Desse modo, a classe burguesa, para se manter como classe dirigente, utiliza aparelhos hegemônicos repressivos e de convencimento.

\footnotetext{
$4 \quad$ Grande parte de sua obra foi escrita durante o período em que esteve no cárcere, e a mais expressiva é Os cadernos do Cárcere, que começou a ser escrita em 1929. As obras desse período foram organizadas posteriormente em agrupamento temático, além de fragmentários em razão do processo de produção e censura. A partir de sua morte sofreram interpretação e organização para publicação, conforme interesses do PCl e de seu organizador, Palmiro Togliatti.
} 
Atualmente, alargaram-se os espaços de dominação via convencimento realizado na sociedade civil, especialmente pela atuação das Fundações privadas e Associações sem fins lucrativos (Fasfil). Estes agentes atuam em diversos âmbitos ${ }^{5}$ no campo educacional, e um dos pontos-chave são as parcerias com as redes educacionais públicas via instâncias de gestão que, desde o contexto de reformas na administração pública, matizaram o público e o privado por meio da publicização (BRASIL, 1995).

Nesse prisma, o presente texto inicia com apontamentos históricos sobre a emergência das Parcerias Público-Privadas (PPP) na esfera administrativa municipal, indicando os principais acontecimentos que impulsionaram sua emergência. A segunda subseção discute as pesquisas identificadas no Catálogo de Teses e Dissertações da CAPES que discorrem a respeito das PPP na esfera administrativa municipal. Por fim, a última subseção problematiza sobre a atuação da classe subalterna para o fomento de outra hegemonia.

\section{APONTAMENTOS HISTÓRICOS SOBRE A EMERGÊNCIA DAS PPP NA ESFERA MUNICIPAL}

Partimos do pressuposto de que há, na sociedade, uma luta entre as classes, em que a classe burguesa possui o intuito de se manter como classe dirigente, e a classe subalterna almeja encontrar meios de ampliar seu espaço de atuação. Assim, os espaços sociais caracterizam-se por uma correlação de forças. Sob a perspectiva marxista, o estudo tem como objetivo investigar o modo pelo qual seja possível a classe subalterna proletariada ter consciência do seu lugar e de sua função para o fomento de mudança do status quo. Em outras palavras, uma mudança revolucionária para chegar a uma sociedade comunista, em que haja a emancipação humana e não apenas a democracia formal, posta pela sociedade atual, capitalista e neoliberal.

Indicamos que a relação entre o Estado, a educação e os setores privados se reestruturou, no Brasil, principalmente, a partir de 1990, por meio da reforma gerencial (BRASIL, 1995). Atualmente, com o discurso emitido pelo governo, principalmente por meio de propagandas midiáticas, sobre a baixa qualidade da educação pública, o setor privado, aos poucos, foi sendo considerado um elemento competente para elevar a qualidade educacional.

0 Instituto Brasileiro de Geografia e Estatística (IBGE) (2012) classifica as Fasfil por grupos: 1) habitação; 2) saúde; 3) cultura e recreação; 4) educação e pesquisa; 5) assistência social; 6) religião; 7) partidos políticos; 8) sindicatos, associações patronais e profissionais; 9) meio ambiente e proteção animal; 10) desenvolvimento e defesa de direitos; e 11) outras instituições privadas sem fins lucrativos. 
Nesse contexto, podemos indicar o pensamento de Gramsci (2016, p. 269, grifos do autor), o qual ressalta que:

0 que se chama de "opinião pública" está estreitamente ligado à hegemonia política, ou seja, é o ponto de contato entre a "sociedade civil" e a "sociedade política", entre o consenso e a força. 0 Estado, quando quer iniciar uma ação pouco popular, cria preventivamente a opinião pública adequada, ou seja, organiza e centraliza certos elementos da sociedade civil.

Nesse sentido, a classe burguesa desenvolve uma unidade de pensamento hegemônico, opinião pública, antes de tomar medidas políticas que teriam resistência de implementação. 0 que significa, em Gramsci, que o Estado burguês trabalha por meio da força e do consenso.

No âmbito da esfera administrativa municipal, segundo Araújo (2013), não foi a pressão dos organismos internacionais que colocou a municipalização em pauta no bojo das reformas da década de 1990, visto que as propostas de municipalização, historicamente, remontam a década de 1920. "Foram sistematizadas por Anísio Teixeira nas décadas seguintes e refutadas por Carlos Correa Mascaro entre as décadas de 1950 e 1960." (ARAÚJ0, 2013, p. 347). Portanto, a questão dos municípios enquanto uma instância administrativa e autônoma é um tema complexo, que requer alguns apontamentos para o entendimento dessa esfera com o âmbito privado.

Os municípios brasileiros possuem características específicas que influenciam no âmbito da gestão e do financiamento de suas localidades para a realização da política educacional municipal. Essas características passam pela discussão acerca da constituição legal brasileira enquanto república federativa, da não implementação de um Sistema Nacional de Ensino (SNE), das discussões sobre a constituição histórica do munícipio enquanto ente federado, e pelo regime de colaboração.

Oficialmente, o Brasil constitui-se como uma República Federativa em que a União, os Estados e os Municípios possuem autonomia, ao mesmo tempo em que exercem suas competências em regime de colaboração. A primeira Constituição republicana brasileira foi a de १८91, sendo considerada o resultado de uma República repleta de contradições. "Proclamada pelo Exército, tendo à frente um monarquista, desde seu nascedouro esta é assinalada por conflitos entre deodoristas e florianistas, que representam os dois segmentos das forças militares que tomam o poder." (VIEIRA, 2007, p. 294). Assim, a república federativa brasileira emerge de forma complexa e patrimonialista, principalmente no que tange ao ente federado municipal (ARAÚJO, 2013). 
0 município foi reconhecido como ente federado, adquirindo consolidação de sua autonomia somente pela Constituição Federal de 1988. 0 que implicou se tornar ente jurídico com recursos e responsabilidades próprias, organizando-se político-administrativamente.

0 Brasil, ainda hoje, não constituiu um SNE. Para Saviani (2014), a falta de um SNE traduz-se em uma desarticulação entre as esferas administrativas, no que concerne às questões econômicas e ideológicas, e mesmo não sendo a raiz do problema, abre margem para as PPP. Significa que é para que a classe burguesa continue exercendo influência com o intuito de se manter como classe hegemônica.

A discussão sobre a desarticulação posta pelas esferas administrativas abre questões quanto às estratégias de descentralização da política governamental brasileira, nos assuntos referentes à gestão educacional, e a mais relevante para a conjuntura atual das PPP foi posta pelas regulações das reformas de 1990. Ao problematizar o termo descentralização, indicamos que existem

[..] possibilidades dos mecanismos descentralizadores articularem-se ou não à perspectiva de democratização. Apesar de ser possivel, a partir da década de 1980, associar o debate sobre os municípios àquele da democratização e descentralização, a emergência da organização municipal no Brasil, muito anterior a isso, se fez mais articulada à necessidade de centralização do poder da Coroa Portuguesa, exatamente na contramão de tal associação. (GOUVEIA, 2008, p. 438).

Desse modo, destacamos que os obstáculos econômicos postos nos munícipios para a concretização das políticas se traduzem nas estratégias de descentralização da política governamental brasileira. Entendemos tal política como um descomprometimento do Estado com relação ao ensino básico. As políticas educacionais são traduzidas pela descontinuidade, principalmente por se tratar de um embate ideológico e político nas discussões de garantias de direitos sociais.

Desde o período do Império, os municípios, apesar "[...] de passarem a ser responsáveis pela instrução, conforme previsto em 1828 na lei de criação das Câmaras Municipais, não dispunham de recursos para tal empreitada." (GOUVEIA, 2008, p. 43). Com a constituição do período republicano, emergiu a chamada política dos coronéis, e, nesse cenário, o descaso com a educação continuou o mesmo. Assim, "[...] a educação ficou posta como um encargo não da centralização política, mas, eminentemente da descentralização política e administrativa, mantendo a tradição do Ato Adicional de 1834."6 (ARAÚJ0, 2013, p. 198).

$6 \quad$ Foi uma medida legislativa tomada durante a Regência Trina Permanente, contemplando os interesses dos grupos liberais. Alterava a Constituição de 1824 e foi uma tentativa de conter os conflitos entre liberais e conservadores nas disputas pelo poder político central (BRASIL, 1834). 
0 que significou mudanças apenas no aspecto legal, e não em maior autonomia local ao que concerne aos aspectos financeiros, cabendo aos estados a responsabilidade pela instrução pública. Percebemos que, desde a sua origem, o município foi uma instância de disputas que servia aos interesses das elites hegemônicas.

Identificamos o surgimento de uma proposta de fortalecimento e implementação do regime de colaboração por meio de Arranjos de Desenvolvimento da Educação (ADE) (ARAÚJO, 2012) que foram realizados em 2011 pelo Conselho Nacional de Educação (CNE). Aprovada pelo Parecer n. 9, essa proposta foi regulamentada pela Resolução n. 1/2012 (BRASIL, 2012).

0 Parecer recomenda uma forma de colaboração diferente da verticalizada entre União, Estado e Municípios. Indica a colaboração entre os municípios, de forma horizontal e por proximidade geográfica. Entendemos que esse movimento desvia o foco da criação de um SNE articulado e necessário para organização das ações administrativas e financeiras dos municípios. Nesse sentido, Araújo (2012), em seu estudo sobre os ADE como medida para que o empresariado regulamente e defina o regime de cooperação, indica que os ADE postos pelo Parecer n. 9 remontam do movimento de elaboração do Plano de Desenvolvimento da Educação (PDE) via Programa Todos pela Educação (TPE) que,

[..] desde 2008, em parceria com os três níveis de governo, fundações e
institutos de empresas, deu início à operacionalização do chamado Arranjo
de Desenvolvimento da Educação (ADE). Para o TPE, o ADE se define por
um trabalho em rede, no qual um grupo de municípios, com proximidade
geográfica e características sociais e econômicas semelhantes, buscam
trocar experiências e solucionar conjuntamente dificuldades na área da
educação. Os primeiros ADE's foram operacionalizados pelo TPE, a partir de
2009 no Recôncavo Baiano, com o apoio do Instituto Votorantim, e na linha
férrea de Carajás (MA), com o apoio da Fundação Vale. (ARAÚJo, 2012, p. 518 ).

Ao analisar o Parecer e a indicação de parcerias, identificamos que o documento ressalta que os

[...] ADEs, não obstante a forte característica intermunicipal, devem agregar a participação do Estado e União, incluindo ou não a participação de instituições privadas e não governamentais, tais como empresas e organizações diversas, que assumem o objetivo comum de contribuir de forma transversal e articulada para o desenvolvimento da educação em determinado território que ultrapassa as lindes de um só Município, sem que haja para isso transferência de recursos públicos para tais instituições e organismos privados. (BRASIL, 2011, grifo nosso). 
Entendemos, em concordância com Araújo (2012), que a implementação dos ADE se traduz como uma medida que substitui o regime de colaboração que seria posto pela constituição do SNE. Esse desvio retira o debate político, democrático e participativo em torno do tema pela indicação e implementação feita pelo modelo empresarial; neste caso, o empresariado ligado ao TPE.

Ainda segundo Araújo (2012, p. 524), os ADE não se traduzem em um caso isolado, eles emergem em um contexto social de globalização e neoliberalismo. Nesse contexto, o conceito de Estado-nação ficou enfraquecido, sendo substituído por uma sociedade baseada em redes, o Estado-região. Nessa perspectiva, Gramsci (1999, p. 399) indica que toda a “[...] relação de 'hegemonia' é necessariamente uma relação pedagógica, que se verifica não apenas no interior de uma nação, entre as diversas forças que a compõem, mas em todo o campo internacional e mundial, entre conjuntos de civilizações nacionais e continentais."

Desse modo, os ADE emergem dos Arranjos Produtivos Locais (APL), pensados como nomenclatura para contemplar as políticas em que o Estado-nação fica responsável por criar ambientes favoráveis, estimulando os investimentos privados dentro de redes ligadas territorialmente. Isso significa o desenvolvimento de uma agenda estratégica tendo o local como referência única, ao mesmo tempo em que não atende a suas particularidades.

A ação posta pelo Parecer não se encontra isolada, ela faz parte de um projeto societário pensado em diferentes níveis, principalmente pela esfera econômica global. Assim, Sheen (2007, p. 5) ressalta que a conquista e o exercício da hegemonia "[...] exigem uma atuação tanto em nível da estrutura quanto da superestrutura, uma vez que a hegemonia se dá em todos os níveis: político, econômico, ideológico e cultural." Seguindo essa ordem de estratégias, criaram-se arranjos que incidem em PPP, as quais foram implementadas no lugar de uma organização sistêmica legal e efetiva. Para tanto, elas incluem uma reforma moral e ideológica, com o intuito de sua naturalização.

Para Gramsci (2016, p. 19), uma reforma "[...] intelectual e moral não pode deixar de estar ligada a um programa de reforma econômica; mais precisamente, o programa de reforma econômica é exatamente o modo concreto através do qual se apresenta toda reforma intelectual moral." Entendemos que todo o movimento posto por uma nova articulação e um não desenvolvimento de um SNE são reformas estratégicas para a classe burguesa se manter enquanto dirigente.

Nesse contexto, os municípios, mesmo sem aporte de um SNE, após as regulamentações da CF 1988, ficaram respaldados legalmente para organizarem seus SME. Entendemos que somente a inclusão legal não basta para efetivar a organização de um SME. Para tanto, são necessárias condições de implementação, articulação com as outras 
esferas administrativas e elaboração de uma proposta pedagógica para além de criação e/ ou desenvolvimento de Conselho e Secretaria.

Araújo e Pinto (2017) indicam que, em decorrência do fenômeno da municipalização, para além da descentralização da gestão e do controle de resultado via avaliações externas, em menos de uma década aumentou a demanda municipal de instrução elementar. Podemos observar esse fato na Tabela 1.

Tabela 1 - Matrículas do ensino obrigatório ${ }^{7}$ por dependência administrativa - 1991 a 2017

\begin{tabular}{rrrrrr}
\hline Ano & Total & Federal & Estadual & Municipal & Privada \\
\hline 1991 & 36.604 .707 & 433.956 & 19.366 .976 & 11.403 .036 & 5.617 .717 \\
2001 & 55.735 .552 & 132.237 & 23.066 .752 & 26.921 .822 & 5.614 .741 \\
2011 & 43.440 .674 & 141.228 & 16.944 .440 & 20.100 .209 & 6.254 .797 \\
$20177^{8}$ & $X$ & $X$ & 13.601 .152 & 18.950 .555 & $X$ \\
\hline
\end{tabular}

Fonte: elaborado pelos autores com base no Instituto Nacional de Estudos e Pesquisas Educacionais Anísio Teixeira (2002, 2003, 2012, 2018).

A esfera municipal, no período de 1991 a 2001, mais que dobrou o seu número de matrículas, sobrecarregando os municípios. Paralelamente, observamos uma reestruturação no que concerne às questões de financiamento, como já enunciado, principalmente com o Fundo de Manutenção e Desenvolvimento do Ensino Fundamental e de Valorização do Magistério (Fundef) e o Programa Dinheiro Direto na Escola (PDDE). Nesse sentido, Bonamino (2003, p. 272) ressalta, nessa restruturação, a estabilização “[...] da tendência a redesenhar um novo arranjo federativo, derivado da transferência de funções, decisões e recursos educacionais do plano federal para os estados e municípios."

Nesse prisma, a solução para o problema manufaturado da gestão educacional na esfera municipal, ocasionado desde a municipalização com o aumento das matrículas, na visão de Araújo (2012), seriam os novos arranjos, os quais indicam uma abertura ao empresariado. Para além da organização no âmbito educacional que incluiu o empresariado, indicamos o papel do discurso emitido pela mídia que, de maneira intencional e estratégica, naturaliza as parcerias. Um exemplo foi posto pela propaganda midiática dos Amigos da Escola, em que cada um tem que fazer a sua parte, retirando a obrigação legal do Estado.

Desse modo, Gruppi (1978, p. 4) indica que a filosofia "[...] não mais precede simplesmente através de conceitos, mas a partir da estrutura econômica, das transformações 
ocorridas nas relações de produção, numa continua relação dialética entre base econômica, estrutura social e consciência dos homens." Assim, sobre a filosofia da classe dominante, Gramsci (1999, p. १14-115) ressalta que elas

\footnotetext{
[...] influem sobre as massas populares como força politica externa, como elemento de força coesiva das classes dirigentes, e, portanto, como elemento de subordinação a uma hegemonia exterior, que limita o pensamento original das massas populares de uma maneira negativa, sem influir positivamente sobre elas, como fermento vital de transformação interna do que as massas pensam, embrionária e caoticamente, sobre o mundo e a vida.
}

Nesse sentido, a filosofia burguesa exerce uma dominação da classe subalterna, tornando-a menos esclarecida. Sob esse ponto de vista, entendemos que o fomento das PPP na esfera administrativa municipal se traduz em uma estratégia posta pela classe burguesa para continuar como classe hegemônica, agindo para além das questões econômicas, para propagar a sua filosofia.

\section{A ATUAÇÃO DOS AGENTES PRIUADOS NA ESFERA ADMINISTRATIUA MUNICIPAL}

A classe burguesa propaga a ideia de que as PPP são indicadas para desenvolver um tipo de educação que forme o cidadão para o trabalho quando, na realidade, é um processo de dominação realizado por meio de uma "nova pedagogia da hegemonia." (NEVES, 2005, 2010). Um tipo de pedagogia que está a serviço da classe burguesa e que perpassa tanto o ensino sistematizado quanto a educação não formal. Entendemos que, dentro das instâncias, há um embate entre as classes, uma correlação de forças, e que o movimento deste estudo é um exemplo dessa correlação.

Com o intuito de entender como ocorrem essas PPP em algumas localidades municipais, fizemos uma pesquisa no Banco de Teses e Dissertações da Capes utilizando os descritores: Agentes privados, Parceria público privada e Parceria público privado, permitindo a localização de, respectivamente, 153, 266 e 35 trabalhos, num total 454. Após a leitura dos resumos, foram selecionados 16 textos. 
Concomitantemente, realizamos uma busca de trabalhos no Portal de Periódicos da Capes, em que seguimos os mesmos descritores. A pesquisa permitiu a localização de, respectivamente, 70, 45 e sete trabalhos. Após análise de seus resumos, selecionamos quatro artigos. Em uma visão geral, o total de trabalhos selecionados foram 20 , sendo 10 dissertações, seis teses e quatro artigos.

Os trabalhos selecionados tiveram como objetivo de análise problematizar e discutir a relação público-privada na esfera administrativa municipal, o que pode ser identificado, de forma geral, por meio de seus títulos no Quadrol.

Quadro 1 - Trabalhos publicados por ano/categoria relação PPP - Brasil - 2018

\begin{tabular}{|c|c|c|c|}
\hline Ano & Categoria & Quantidade & Título \\
\hline 2007 & Artigo & 01 & A análise do programa "Bolsa Creche" no Município de Piracicaba/SP. \\
\hline 2010 & Artigo & 01 & $\begin{array}{l}\text { Comparação entre os sistemas de gestão privados adotados pelos } \\
\text { Municípios de São José dos Campos e Cosmorama. }\end{array}$ \\
\hline 2011 & Artigo & 01 & Adoção de Sistema de Ensino Apostilado em lpeúna, SP. \\
\hline 2012 & Artigo & 01 & $\begin{array}{l}\text { Breve retrato da atuação dos Grupos Empresariais Objetivo, COC e } \\
\text { Positivo nos municípios do estado de São Paulo. }\end{array}$ \\
\hline \multirow{3}{*}{2013} & Tese & 01 & $\begin{array}{l}0 \text { Programa Gestão Nota } 10 \text { do Instituto Ayrton Senna e a Educação } \\
\text { em Santarém-PA }\end{array}$ \\
\hline & \multirow[t]{2}{*}{ Dissertação } & \multirow[t]{2}{*}{02} & $\begin{array}{l}\text { Formação continuada de professores e a municipalização do ensino: } \\
0 \text { processo de parceria entre municípios e sistemas privados de } \\
\text { ensino no Polo } 20 \text { da UNCME-SP. }\end{array}$ \\
\hline & & & $\begin{array}{l}\text { Projeto "Educação Repaginada" de Salto/SP: contradições de uma } \\
\text { alternativa à adoção de "sistemas privados de ensino". }\end{array}$ \\
\hline \multirow{5}{*}{2014} & \multirow{2}{*}{ Dissertação } & \multirow{2}{*}{02} & $\begin{array}{l}\text { Parceria Público/Privada em Educação: análise do Projeto Alfabetizar } \\
\text { com Sucesso/Programa Circuito Campeão no município de Surubim/PE. }\end{array}$ \\
\hline & & & $\begin{array}{l}\text { A prática do Instituto Ayrton Senna na rede pública municipal de } \\
\text { educação em São José dos Pinhais/PR. }\end{array}$ \\
\hline & \multirow{3}{*}{ Tese } & \multirow{3}{*}{03} & $\begin{array}{l}\text { A Parceria Público-Privada do Instituto Ayrton Senna e a prefeitura } \\
\text { municipal de Benevides-PA: entre os desafios (pro)postos e os limites } \\
\text { da realidade. }\end{array}$ \\
\hline & & & $\begin{array}{l}\text { A organização do trabalho pedagógico na escola e o sistema aposti- } \\
\text { lado de ensino: estudo de caso. }\end{array}$ \\
\hline & & & $\begin{array}{l}\text { A lógica do mercado na Educação pública municipal - a parceria } \\
\text { público-privada em Catalão/Goiás. }\end{array}$ \\
\hline 2015 & Dissertação & 01 & $\begin{array}{l}\text { A oferta educacional na educação infantil: um estudo dos convenia- } \\
\text { mentos em municípios pequenos do interior paulista. }\end{array}$ \\
\hline
\end{tabular}




\begin{tabular}{|c|c|c|c|}
\hline Ano & Categoria & Quantidade & Título \\
\hline \multirow{7}{*}{2016} & \multirow{2}{*}{ Tese } & \multirow{2}{*}{02} & $\begin{array}{l}\text { A cogestão dos Centros de Educação Infantil "Nave-mãe": uma } \\
\text { parceria público-privada analisada }\end{array}$ \\
\hline & & & $\begin{array}{l}\text { Parceria público-privada em educação: arranjos de educação em } \\
\text { municípios do Vale do Jequitinhonha e a Fundação Vale. }\end{array}$ \\
\hline & \multirow{5}{*}{ Dissertação } & \multirow{5}{*}{05} & $\begin{array}{l}\text { A participação das instituições não governamentais na gestão da } \\
\text { escola pública: uma análise do Programa "Nave-Mãe" no Município de } \\
\text { Campinas-SP. }\end{array}$ \\
\hline & & & $\begin{array}{l}\text { Matrícula obrigatória na educação infantil: impactos no município de } \\
\text { Santa Maria - RS. }\end{array}$ \\
\hline & & & $\begin{array}{l}0 \text { projeto autonomia carioca: parceria público-privada no ensino } \\
\text { fundamental do município do Rio de Janeiro (2010-2014). }\end{array}$ \\
\hline & & & $\begin{array}{l}\text { Formação docente e educação a distância no município de Água } \\
\text { Branca-AL: limites e possibilidades de superação. }\end{array}$ \\
\hline & & & $\begin{array}{l}\text { Educação infantil e as relações público-privado no município de } \\
\text { Campinas: o programa Naves-Mãe. }\end{array}$ \\
\hline
\end{tabular}

Fonte: os autores.

A partir da leitura dos resumos, apontamos os seguintes questionamentos: que temáticas e objetivos foram contemplados nas pesquisas sobre as PPP nesses trabalhos? Que resultados foram explicitados? Nesse sentido, para organizar a exposição, os trabalhos foram sistematizados em três grupos. 0 primeiro trata das pesquisas sobre as PPP no que concerne aos materiais didáticos e apostilamentos:

Quadro 2 - Trabalhos: PPP Apostilamento/Material Didático - 2018

\begin{tabular}{|c|c|c|c|}
\hline Objeto de estudo & Área(s) & Metodologia & Resultados apontados \\
\hline $\begin{array}{l}\text { Parceria entre a } \\
\text { Secretaria Municipal } \\
\text { de Educação de } \\
\text { Catalão/G0 com } \\
\text { a Editora Positivo } \\
\text { Ltda. }\end{array}$ & $\begin{array}{l}\text { Educação: } \\
\text { tese }\end{array}$ & $\begin{array}{l}\text { Revisão de literatura, } \\
\text { levantamento e análise } \\
\text { documental, entrevistas se- } \\
\text { miestruturadas e utilização } \\
\text { de questionários. }\end{array}$ & $\begin{array}{l}\text { Internalização e naturalização de que } \\
\text { tudo que envolve a educação pública } \\
\text { pode ser convertido em bens e pro- } \\
\text { dutos comercializáveis. Fetichização } \\
\text { dos produtos, serviços e tecnologias } \\
\text { educacionais. }\end{array}$ \\
\hline
\end{tabular}




\begin{tabular}{|c|c|c|c|}
\hline Objeto de estudo & Áreals) & Metodologia & Resultados apontados \\
\hline $\begin{array}{l}\text { Ações de formação } \\
\text { continuada de } \\
\text { professores em } \\
\text { municípios que } \\
\text { compraram mate- } \\
\text { riais apostilados de } \\
\text { sistemas de ensino } \\
\text { privados no Polo } 20 \\
\text { da UNCME-SP. }\end{array}$ & $\begin{array}{l}\text { Educação: } \\
\text { disserta- } \\
\text { ção }\end{array}$ & $\begin{array}{l}\text { Dois momentos: 1) levanta- } \\
\text { mento de dados educa- } \\
\text { cionais dos municípios } \\
\text { investigados nos bancos de } \\
\text { dados de vários órgãos; 2) } \\
\text { o emprego de abordagem } \\
\text { metodológica de natureza } \\
\text { qualitativa, com entrevistas } \\
\text { semiestruturadas. }\end{array}$ & $\begin{array}{l}\text { As ações de formação continuada de } \\
\text { docentes promovidas pelas empre- } \\
\text { sas que se centram em um modelo } \\
\text { de formação individual do professor } \\
\text { e na transmissão de conteúdos } \\
\text { preestabelecidos, constituindo-se } \\
\text { em ação basicamente instrumental. } \\
\text { Torna-se clara a necessidade de } \\
\text { que a formação continuada não seja } \\
\text { vista como um amontoado de cursos } \\
\text { esporádicos e fragmentados. }\end{array}$ \\
\hline $\begin{array}{l}\text { Uso do sistema } \\
\text { apostilado de } \\
\text { ensino enquanto } \\
\text { material estrutura- } \\
\text { do para a organi- } \\
\text { zação do trabalho } \\
\text { pedagógico na } \\
\text { escola. }\end{array}$ & $\begin{array}{l}\text { Educação } \\
\text { escolar: } \\
\text { tese }\end{array}$ & $\begin{array}{l}\text { Pesquisa qualitativa, por meio } \\
\text { de estudo de caso em um } \\
\text { município paulista, em duas } \\
\text { escolas públicas municipais } \\
\text { que atendem exclusivamente } \\
\text { os anos iniciais do Ensino } \\
\text { Fundamental. }\end{array}$ & $\begin{array}{l}0 \text { uso do sistema apostilado de } \\
\text { ensino interfere na organização do } \\
\text { trabalho pedagógico e no Projeto } \\
\text { Politico Pedagógico das escolas, } \\
\text { ao padronizar e homogeneizar o } \\
\text { conteúdo curricular e ao excluir } \\
\text { os professores da autoria de seu } \\
\text { próprio trabalho. No entanto, nas } \\
\text { escolas residem possibilidades para } \\
\text { o exercício da autonomia escolar. }\end{array}$ \\
\hline $\begin{array}{l}\text { Implantação e as } \\
\text { consequências da } \\
\text { parceria púbico-pri- } \\
\text { vada no Município } \\
\text { de lpeúna, Estado } \\
\text { de São Paulo, } \\
\text { quanto à compra } \\
\text { de sistema de } \\
\text { ensino apostilado. }\end{array}$ & $\begin{array}{l}\text { Educação: } \\
\text { artigo }\end{array}$ & $\begin{array}{l}\text { Levantamento de dados } \\
\text { demográficos, financeiros } \\
\text { e educacionais, realização } \\
\text { de entrevistas semiestrutu- } \\
\text { radas, consultas aos sites } \\
\text { governamentais. }\end{array}$ & $\begin{array}{l}\text { Verificou-se que houve alterações } \\
\text { na política educacional municipal, } \\
\text { alterou-se o lócus decisório quanto } \\
\text { à seleção e organização dos conte- } \\
\text { údos curriculares e quanto à forma- } \\
\text { ção de professores, transferindo-os } \\
\text { para o sistema de ensino. }\end{array}$ \\
\hline $\begin{array}{l}\text { Três Grupos } \\
\text { Empresariais - 0b- } \\
\text { jetivo, COC e Positivo } \\
\text { - e caracterização } \\
\text { dos produtos } \\
\text { e serviços que } \\
\text { integram seus sis- } \\
\text { temas apostilados } \\
\text { de ensino. }\end{array}$ & $\begin{array}{l}\text { Educação: } \\
\text { artigo }\end{array}$ & $\begin{array}{l}\text { Levantamento realizado } \\
\text { durante desenvolvimento } \\
\text { de pesquisas de Iniciação } \\
\text { Científica. }\end{array}$ & $\begin{array}{l}\text { Observam-se muitas semelhanças na } \\
\text { trajetória e na atuação desses três } \\
\text { grupos e uma intensa e crescente } \\
\text { oferta de seus respectivos sistemas } \\
\text { de ensino para as redes públicas, } \\
\text { gerando consequências, como pa- } \\
\text { dronização de conteúdos escolares, } \\
\text { padronização de qualidade e transfe- } \\
\text { rência de responsabilidades do setor } \\
\text { púbico para a esfera privada. }\end{array}$ \\
\hline
\end{tabular}

Fonte: os autores. 
Identificamos que, das cinco pesquisas, três indicam que realizaram entrevistas semiestruturadas, duas indicam natureza qualitativa, e todas fizeram levantamento e análise documental. Quanto aos resultados, nenhuma pesquisa indicou pontos positivos. Elas ressaltaram a desresponsabilização do âmbito público, a homogeneização dos conteúdos curriculares, bem como o entendimento de que o âmbito educacional público pode ser convertido em bens e produtos comercializáveis.

No segundo grupo, localizamos as pesquisas que tratam das PPP no que concerne aos Arranjos, Educação a distância (EAD) e convênios na Educação Infantil.

Quadro 3 - Trabalhos PPP - Arranjos/EAD/Conveniamentos - 2018

\begin{tabular}{|c|c|c|c|}
\hline Objeto de estudo & Areals) & Metodologia & Resultados apontados \\
\hline $\begin{array}{l}\text { Parcerias entre o } \\
\text { público e o privado } \\
\text { realizadas por } \\
\text { municípios paulis- } \\
\text { tas para a oferta } \\
\text { educacional na } \\
\text { Educação Infantil }\end{array}$ & $\begin{array}{l}\text { Educação: } \\
\text { disserta- } \\
\text { ção }\end{array}$ & $\begin{array}{l}\text { Foi realizado com uma amostra } \\
\text { de } 50 \% \text { dos } 56 \text { municípios } \\
\text { pequenos (de } 10.001 \text { a } 50.000 \text { hab.) } \\
\text { que declararam possuir parcerias } \\
\text { para a oferta de Educação } \\
\text { Infantil. }\end{array}$ & $\begin{array}{l}\text { Os resultados evidenciam que os } \\
\text { convênios, legitimados pela atual } \\
\text { legislação e impulsionados tanto } \\
\text { pela esfera pública quanto pela } \\
\text { privada, estão em expansão, e em } \\
\text { alguns municípios representam a } \\
\text { única forma de atender a essa } \\
\text { faixa etária. }\end{array}$ \\
\hline $\begin{array}{l}\text { Processo de } \\
\text { implementação do } \\
\text { projeto Educação } \\
\text { Repaginada e suas } \\
\text { contradições. }\end{array}$ & $\begin{array}{l}\text { Educação: } \\
\text { disserta- } \\
\text { ção }\end{array}$ & $\begin{array}{l}\text { Estudo de caso em uma aborda- } \\
\text { gem qualitativa, na qual se utilizou } \\
\text { como recurso metodológico a } \\
\text { pesquisa documental sobre a } \\
\text { educação municipal de Salto e } \\
\text { entrevistas semiestruturadas. }\end{array}$ & $\begin{array}{l}\text { Apesar dos limites e das con- } \\
\text { tradições, o projeto Educação } \\
\text { Repaginada reflete a posição } \\
\text { da gestão educacional de Salto } \\
\text { em ser contrária às políticas de } \\
\text { desqualificação da gestão pública, } \\
\text { disseminadas em vários municípios } \\
\text { paulistas, pós-municipalização do } \\
\text { Ensino Fundamental. }\end{array}$ \\
\hline
\end{tabular}




\begin{tabular}{|c|c|c|c|}
\hline Objeto de estudo & Areals) & Metodologia & Resultados apontados \\
\hline $\begin{array}{l}\text { Projeto Autono- } \\
\text { mia Carioca: uma } \\
\text { aceleração de } \\
\text { estudos destinada } \\
\text { a alunos em } \\
\text { defasagem de } \\
\text { idade/série matri- } \\
\text { culados no Ensino } \\
\text { Fundamental nas } \\
\text { escolas públicas } \\
\text { municipais do Rio } \\
\text { de Janeiro. }\end{array}$ & $\begin{array}{l}\text { Educação: } \\
\text { disserta- } \\
\text { ção }\end{array}$ & $\begin{array}{l}\text { Os referenciais teóricos do } \\
\text { estudo estão relacionados aos } \\
\text { conceitos: educação formal e } \\
\text { educação não formal, e Terceiro } \\
\text { Setor, parceria público-privada na } \\
\text { educação. Coleta de dados em } \\
\text { documentos oficiais divulgados } \\
\text { em sites e, depois, por meio de } \\
\text { entrevistas semiestruturadas } \\
\text { com professoras da } 5^{\circ} \text { CRE. }\end{array}$ & $\begin{array}{l}\text { Apesar de apontarem alguns } \\
\text { problemas nas dinâmicas da } \\
\text { telessala, como a inadequação } \\
\text { dos vídeos aos alunos do projeto, } \\
\text { a dificuldade no trabalho das } \\
\text { equipes e o pouco contato com } \\
\text { os responsáveis, as professo- } \\
\text { ras veem, nessa aceleração de } \\
\text { estudos, uma forma de observar } \\
\text { melhor o aluno em suas dificul- } \\
\text { dades, não só de conteúdos, mas } \\
\text { também em questões comporta- } \\
\text { mentais, até pelo tempo maior na } \\
\text { sala de aula com eles. }\end{array}$ \\
\hline $\begin{array}{l}\text { Parcerias público- } \\
\text {-privadas orga- } \\
\text { nizadas a partir } \\
\text { de arranjos de } \\
\text { desenvolvimento. }\end{array}$ & $\begin{array}{l}\text { Educação: } \\
\text { tese }\end{array}$ & $\begin{array}{l}\text { Foram selecionados três munici- } \\
\text { pios partícipes de um arranjo de- } \\
\text { nominado Jequitinhonha, a saber: } \\
\text { Carbonita, Turmalina e Leme do } \\
\text { Prado. Diante do objetivo propos- } \\
\text { to, optou-se pela realização de } \\
\text { uma pesquisa documental. }\end{array}$ & $\begin{array}{l}\text { Pode-se afirmar, dentre os } \\
\text { direcionamentos, que a parceria } \\
\text { público-privada em questão pro- } \\
\text { porcionou uma mobilização política } \\
\text { junto aos municípios partícipes da } \\
\text { parceria, no sentido de estimular } \\
\text { os gestores municipais para a } \\
\text { construção do Plano de ações } \\
\text { articuladas (PAR), com bases } \\
\text { pactuadas com a população. }\end{array}$ \\
\hline $\begin{array}{l}\text { As políticas de } \\
\text { Educação Infantil } \\
\text { do Município de } \\
\text { Santa Maria, RS, a } \\
\text { partir da Emenda } \\
\text { Constitucional } \\
\text { n. } 59 .\end{array}$ & $\begin{array}{l}\text { Educação: } \\
\text { disserta- } \\
\text { ção }\end{array}$ & $\begin{array}{l}\text { Abordagem qualitativa do tipo } \\
\text { estudo de caso, análise de dados } \\
\text { estatísticos do Censo Escolar e } \\
\text { dados sistematizados pelo Tribu- } \\
\text { nal de Contas do Estado do Rio } \\
\text { Grande do Sul e entrevista. }\end{array}$ & $\begin{array}{l}\text { As ações da Prefeitura para } \\
\text { expandir o acesso à Educa- } \\
\text { ção Infantil estão pautadas na } \\
\text { compra de vagas em instituições } \\
\text { privadas de ensino do Município, } \\
\text { fortalecendo, assim, a parceria } \\
\text { público-privada. }\end{array}$ \\
\hline
\end{tabular}




\begin{tabular}{|c|c|c|c|}
\hline Objeto de estudo & Areals) & Metodologia & Resultados apontados \\
\hline $\begin{array}{l}\text { Os limites da } \\
\text { formação de pro- } \\
\text { fessores via edu- } \\
\text { cação a distância } \\
\text { (EAD), fomentada } \\
\text { pela ideologia } \\
\text { neoliberalista, com } \\
\text { base na política } \\
\text { educacional para } \\
\text { a formação inicial } \\
\text { de professores } \\
\text { no Município de } \\
\text { Água Branca, AL, } \\
\text { entre os anos } \\
2006-2014 .\end{array}$ & $\begin{array}{l}\text { Educação: } \\
\text { disserta- } \\
\text { ção }\end{array}$ & $\begin{array}{l}\text { Pesquisa bibliográfica, documental } \\
\text { e de entrevistas com alunos } \\
\text { da EAD, análise que parte da } \\
\text { relação existente entre educação } \\
\text { e sociedade capitalista, tendo } \\
\text { como elementos condutores: leis, } \\
\text { decretos, contrato de parceria } \\
\text { público-privada na oferta de } \\
\text { ensino superior em Água Branca, } \\
\text { AL. }\end{array}$ & $\begin{array}{l}\text { Apontam para a necessidade } \\
\text { de superação da modalidade de } \\
\text { formação de professores via EAD, } \\
\text { uma vez que ela descaracteri- } \\
\text { za a função social do docente } \\
\text { e apresenta limitações, como: } \\
\text { ineficiência do material didático, } \\
\text { indisponibilidade de bibliotecas } \\
\text { e laboratórios adequados na } \\
\text { unidade de formação, tutores } \\
\text { treinados apenas para o exerćicio } \\
\text { de atividades de cunho técnico, } \\
\text { infraestrutura precária e ausência } \\
\text { total de discussão teórica durante } \\
\text { o processo de formação do } \\
\text { professor. }\end{array}$ \\
\hline $\begin{array}{l}\text { Uma análise do } \\
\text { Programa Bolsa } \\
\text { Creche no Munici- } \\
\text { pio de Piracicaba, } \\
\text { SP }\end{array}$ & $\begin{array}{l}\text { Educação: } \\
\text { artigo }\end{array}$ & $\begin{array}{l}\text { Apresentar uma informação preli- } \\
\text { minar sobre a implantação da Lei } \\
\text { Municipal n. } 5.081 \text {, sancionada no } \\
\text { Município de Piracicaba a partir de } \\
19 \text { de dezembro de } 2001 \text {. }\end{array}$ & $\begin{array}{l}\text { Neste trabalho, implantação } \\
\text { significa a ação do governo para } \\
\text { introduzir, inserir e instituir a } \\
\text { proposta educacional. } 0 \text { convênio } \\
\text { tem consumido ano a ano valores } \\
\text { absolutos cada vez maiores do } \\
\text { orçamento público. }\end{array}$ \\
\hline
\end{tabular}

Fonte: os autores.

Nesse grupo, três pesquisas indicam que as PPP, em alguns municípios, são a única forma de atendimento da Educação Infantil, e para além da desresponsabilização do setor público está a questão de financiamento. No terceiro grupo selecionamos as pesquisas que buscam a compreensão das PPP no que concerne ao âmbito da gestão.

Quadro 4 - Trabalhos PPP - Parceria de Gestão - 2018

\begin{tabular}{|c|c|c|c|}
\hline Objeto de estudo & Áreals) & Metodologia & Resultados apontados \\
\hline $\begin{array}{l}\text { Parceria público-privada } \\
\text { entre a Prefeitura Municipal } \\
\text { de Santarém, PA, e o Instituto } \\
\text { Ayrton Senna, por meio da } \\
\text { Rede Vencer, com foco no } \\
\text { Programa Gestão Nota } 10 \\
\text { (PGN10). }\end{array}$ & $\begin{array}{l}\text { Educação: } \\
\text { tese }\end{array}$ & $\begin{array}{l}\text { Análise de documentos so- } \\
\text { bre a legislação educacional, } \\
\text { relatórios de gestão, rela- } \\
\text { tórios sobre a organização } \\
\text { da rede municipal de ensino, } \\
\text { documentos da parceria } \\
\text { público-privada e entrevistas } \\
\text { semiestruturadas. }\end{array}$ & $\begin{array}{l}\text { Serve para alimentar esses } \\
\text { setores privados com dinhei- } \\
\text { ro público em troca da apli- } \\
\text { cação de algumas técnicas } \\
\text { de gestão gerencial no setor } \\
\text { educacional. Intensificação } \\
\text { em cima do trabalho do } \\
\text { professor. }\end{array}$ \\
\hline
\end{tabular}




\begin{tabular}{|c|c|c|c|}
\hline Objeto de estudo & Áreals) & Metodologia & Resultados apontados \\
\hline $\begin{array}{l}\text { A relação da parceria entre } \\
\text { o Instituto Ayrton Senna (IAS) } \\
\text { e a Prefeitura Municipal de } \\
\text { Benevides (PMB), executada } \\
\text { por meio dos Programas } \\
\text { Acelera Brasil e Se Liga. }\end{array}$ & $\begin{array}{l}\text { Educação: } \\
\text { tese }\end{array}$ & $\begin{array}{l}\text { Pautou-se no materialismo } \\
\text { histórico-dialético. Estudo } \\
\text { de caso, cujas fontes pri- } \\
\text { vilegiadas para a obtenção } \\
\text { dos dados centraram-se } \\
\text { em entrevistas semiestru- } \\
\text { turadas. }\end{array}$ & $\begin{array}{l}\text { Orientações e propostas } \\
\text { pautadas em critérios } \\
\text { gerenciais para promover } \\
\text { a concorrência entre as } \\
\text { instituições públicas. Inten- } \\
\text { sificação no trabalho dos } \\
\text { professores. }\end{array}$ \\
\hline $\begin{array}{l}\text { Programa de Atendimento } \\
\text { Especial à Educação Infantil } \\
\text { (PAEEI) vigente no Município } \\
\text { paulista de Campinas, o } \\
\text { poder público transfere a } \\
\text { gestão de equipamentos pú- } \\
\text { blicos denominados Centros } \\
\text { de Educação Infantil Naves- } \\
\text {-mães ao setor privado. }\end{array}$ & $\begin{array}{l}\text { Educação: } \\
\text { tese }\end{array}$ & $\begin{array}{l}\text { Análise de documentos de } \\
\text { fontes primárias referentes } \\
\text { ao quadro educacional, ao } \\
\text { perfil de gasto municipal e à } \\
\text { normalização da implantação } \\
\text { e gestão dos CEl. }\end{array}$ & $\begin{array}{l}\text { Criou desigualdades no } \\
\text { padrão de atendimento } \\
\text { à criança menor de seis } \\
\text { anos, inserindo a Educação } \\
\text { Infantil em uma indústria de } \\
\text { serviços pautados em meca- } \\
\text { nismos de mercado. }\end{array}$ \\
\hline $\begin{array}{l}\text { Parcerias do setor privado } \\
\text { com o setor público na } \\
\text { educação do Estado de } \\
\text { Pernambuco por intermédio } \\
\text { do Instituto Ayrton Senna. }\end{array}$ & $\begin{array}{l}\text { Educação: } \\
\text { disserta- } \\
\text { ção }\end{array}$ & $\begin{array}{l}\text { Pesquisa qualitativa e entre- } \\
\text { vistas semiestruturadas. }\end{array}$ & $\begin{array}{l}\text { Permitiu a aproximação dos } \\
\text { discursos que circundam } \\
\text { a política educacional no } \\
\text { contexto apresentado. }\end{array}$ \\
\hline $\begin{array}{l}\text { Parceria para a gestão da } \\
\text { educação municipal firmada } \\
\text { entre o Instituto Ayrton } \\
\text { Senna (IAS) e a Prefeitura de } \\
\text { São José dos Pinhais. }\end{array}$ & $\begin{array}{l}\text { Educação: } \\
\text { disserta- } \\
\text { ção }\end{array}$ & $\begin{array}{l}\text { Estudo exploratório, de base } \\
\text { bibliográfica e documental, } \\
\text { entrevistas semiestrutu- } \\
\text { radas. }\end{array}$ & $\begin{array}{l}\text { Foi importante para } \\
\text { estabelecer mecanismos } \\
\text { de autonomia, porém tendo } \\
\text { como base competitividade e } \\
\text { busca de resultados. }\end{array}$ \\
\hline $\begin{array}{l}\text { Programa de Atendimento } \\
\text { Especial à Educação Infantil } \\
\text { (PAEEI) instituído no Município } \\
\text { de Campinas, SP, criação dos } \\
\text { CEl Naves-Mães. }\end{array}$ & $\begin{array}{l}\text { Educação: } \\
\text { disserta- } \\
\text { ção }\end{array}$ & $\begin{array}{l}\text { Levantamento teórico } \\
\text { concernente ao tema da } \\
\text { pesquisa, análise documental } \\
\text { e entrevistas semiestrutu- } \\
\text { radas. }\end{array}$ & $\begin{array}{l}\text { Processo de privatização } \\
\text { da Educação Infantil em } \\
\text { Campinas, os baixos salários } \\
\text { pagos aos profissionais, } \\
\text { as salas superlotadas e } \\
\text { o interesse de algumas } \\
\text { instituições em firmarem } \\
\text { parceria. }\end{array}$ \\
\hline $\begin{array}{l}\text { Trajetória, avanços e as } \\
\text { possibilidades do Programa } \\
\text { Naves-Mãe, parceria público- } \\
\text {-privada criada para atender } \\
\text { à demanda de vagas para } \\
\text { as crianças da Educação } \\
\text { Infantil em Campinas. }\end{array}$ & $\begin{array}{l}\text { Educação: } \\
\text { disserta- } \\
\text { ção }\end{array}$ & $\begin{array}{l}\text { Estudo qualitativo interpreta- } \\
\text { tivo que emprega metodolo- } \\
\text { gia das ciências sociais, aná- } \\
\text { lise de documentos oficiais e } \\
\text { outras fontes primárias por } \\
\text { meio de observações e en- } \\
\text { trevistas semiestruturadas. }\end{array}$ & $\begin{array}{l}\text { Aponta para a não garantia } \\
\text { dos direitos das crianças } \\
\text { pequenas a uma educação } \\
\text { gratuita e de qualidade, em } \\
\text { decorrência da precariedade } \\
\text { do atendimento nas Naves- } \\
\text {-Mãe. }\end{array}$ \\
\hline
\end{tabular}




\begin{tabular}{|l|l|l|l|}
\hline \multicolumn{1}{|c|}{ Objeto de estudo } & Área(s) & Metodologia & \multicolumn{1}{c|}{\begin{tabular}{c} 
Resultados apontados \\
\hline
\end{tabular}} \\
$\begin{array}{l}\text { Os sistemas de gestão } \\
\text { adotados por dois municípios } \\
\text { paulistas, Cosmorama e São } \\
\text { José dos Campos. }\end{array}$ & $\begin{array}{l}\text { Educação: } \\
\text { artigo }\end{array}$ & $\begin{array}{l}\text { Foram levantados, selecio- } \\
\text { nados e analisados dados } \\
\text { de matrículas disponibilizados } \\
\text { em banco de dados do } \\
\text { Greppe e sites governa- } \\
\text { mentais. Entrevistas do tipo } \\
\text { semiestruturado. }\end{array}$ & $\begin{array}{l}\text { Baseada em moldes } \\
\text { empresariais, pode alterar o } \\
\text { cotidiano escolar na busca } \\
\text { de resultados melhores e } \\
\text { sistematizados, incentivando } \\
\text { a concorrência entre os } \\
\text { alunos que são homogenei- } \\
\text { zados por metas. }\end{array}$ \\
\hline
\end{tabular}

Fonte: os autores.

Nesse último grupo ressaltamos os trabalhos que tiveram como objeto de estudo o Instituto Ayrton Senna (IAS). Eles concluíram que as PPP firmadas intensificam o trabalho do professor e são pautadas com base na competitividade e na busca por resultados.

Destacaram-se duas teses e uma dissertação concernentes às PPP no Município de Campinas, SP, que tiveram como objeto o Programa Naves-mãe. Elas indicam que está ocorrendo um processo de privatização da Educação Infantil no Município. Ressaltam o baixo valor pago aos profissionais e as salas superlotadas, dificultando a garantia do direito à educação das crianças desse segmento educacional.

As pesquisas, de forma geral, em razão de alguns grupos de estudos, ${ }^{10}$ concentram-se na região Sudeste - São Paulo. Das 20 pesquisas elencadas, 11 localizam-se na região de São Paulo, e apenas uma no Estado do Paraná.

Entendemos, a partir desse levantamento, que os agentes privados, aproveitandose desse nicho econômico que se tornou a abertura posta pelas PPP, vendem seus produtos identificados como apostilamentos, formação continuada dos professores, formação de gestores, programas de gestão, etc. Seu intuito está para além do financeiro, encontra-se na propagação da ideologia burguesa.

\section{PARA CONCLUIR: O CONCEITO DE HEGEMONIA E A CLASSE SUBALTERNA}

Identificamos que as PPP no âmbito municipal se iniciaram, principalmente, por uma desarticulação no regime de colaboração e uma descontinuidade administrativa e política.

10 Como o GREPPE da Unicamp, SP. Mais informações disponiveis em: Grupo de Estudos e Pesquisa em Políticas Educacionais ([20--?]). 
Verificamos que o resultado das PPP, em algumas localidades, foi a desobrigação do aparelho estatal quanto ao cumprimento do direito à educação, baixos salários dos professores e salas superlotadas. Ainda, uma privatização quase direta da Educação Infantil em algumas localidades.

Após a exposição sobre a realidade que se encontra em alguns municípios brasileiros quanto à entrada dos agentes privados no âmbito que seria de direito público educacional, problematizamos: nesse âmbito, o que os subalternos, no caso os educadores, poderiam fazer no sentido de fomentar outra hegemonia? Entre outras questões, essa em especial remete "[...] à complexa tessitura do pensamento gramsciano, em que as reflexões sobre a subalternidade aparecem dialeticamente interligadas com o Estado, a sociedade civil e a hegemonia." (SIMIONATTO, 2009, p. 42).

Nesse sentido, ressaltamos que a perspectiva gramsciana indica que a classe subalterna precisa se organizar e construir novos modos de ação e concepção de mundo, próprios e críticos, desvinculados da filosofia burguesa. Tais modos são necessários e devem ser comprometidos com a transformação social e o trabalho associado. Nesse intento, a filosofia da práxis é o movimento e a teoria indicados pra o fomento de uma verdadeira filosofia do proletariado.

Após as nossas análises, podemos realizar algumas intersecções da teoria com a prática. A classe burguesa comumente desenvolve uma educação diferente para a classe subalterna e para a elite dominante. Para a classe subalterna, uma educação voltada ao trabalho assalariado; às elites, uma educação voltada à direção das classes. Nesse sentido, a educação propagada pelas PPP, voltada para o trabalho como sinônimo de qualidade, não é a mesma educação de qualidade oferecida para a classe dominante.

A qualidade educacional para o proletariado, segundo Gramsci (1976, p. 101), seria posta por

\footnotetext{
[...] uma escola desinteressada. Uma escola em que seja dada a criança a possibilidade de formar-se, de se tornar homem, de adquirir os princípios gerais que servem para $\circ$ desenvolvimento do caráter. Uma escola humanista, em suma, como a entendiam os antigos e os mais recentes homens do Renascimento. Uma escola que não hipoteque o futuro da criança e não obrigue a sua vontade, a sua inteligência e a sua consciência em formação a mover-se num sentido pré-estabelecido. Uma escola de liberdade e de livre iniciativa e não uma escola de escravidão e mecânica.
}

Para Gramsci (1976), uma escola de qualidade está para além de uma formação voltada para o trabalho assalariado e explorador; a qualidade consiste em uma escola desinteressada em que haja uma formação humanista, que englobe o trabalho como ato 
fundante do ser social. Também, que o aluno não possua uma formação pré-determinada. Nesse sentido, a escola de qualidade propagada pela classe burguesa seria uma escola denominada por Gramsci como interessada, em que a elite dominante educa a classe subalterna para o trabalho assalariado, incutindo nos subalternos uma cultura burguesa de submissão.

Assim, superar o senso comum no seio social, que tem como base a filosofia burguesa, significa "[...] redirecionar a práxis política no sentido de propiciar às classes subalternas a libertação das formas de pensar homogeneizadas pelo pensamento liberal e o fortalecimento de seus projetos e ações na construção de uma contra-hegemonia" (SIMIONATTO, 2009, p. 45), ou seja, a construção de outra hegemonia que supere a hegemonia capitalista burguesa. Gramsci (1999, p. 103, grifo do autor) indica que

\footnotetext{
A compreensão crítica de si mesmo é obtida, portanto, através de uma luta de "hegemonias" políticas, de direções contrastantes, primeiro no campo da ética, depois no da política, atingindo, finalmente, uma elaboração superior da própria concepção do real. A consciência de fazer parte de uma determinada força hegemônica (isto é, a consciência política) é a primeira fase de uma ulterior e progressiva autoconsciência, na qual teoria e prática finalmente se unificam.
}

Nesse sentido, para Flach e Schlesener (2018, p. 8), todas as pessoas deveriam ter acesso ao conhecimento relativo "à filosofia, às ciências, às artes, à gramática, à literatura, etc.", bem como condições para seu acesso. Desse modo, o trabalho pedagógico desenvolvido pela autonomia dos alunos deve ser "sem constrangimentos e sem metas prefixadas", ou seja, uma escola "de e para a liberdade, tanto individual quanto coletiva." (FLACH; SCHLESENER, 2017, p. 8).

$\mathrm{Na}$ contramão dessa indicação vimos, na seção anterior, que as pesquisas ressaltaram a desresponsabilização do âmbito público, a homogeneização dos conteúdos curriculares, bem como o entendimento de que o âmbito educacional público pode ser convertido em bens e produtos comercializáveis. Ainda, a intensificação do trabalho do professor, pautada na competitividade e na busca por resultados.

Esses resultados indicam a urgência da formação de outra hegemonia. Seguir esse caminho, "[...] no entanto, implica, para o pensador italiano, travar uma batalha não restrita ao terreno econômico, mas abrangendo também os fronts da cultura, das ideias e dos valores." (SIMIONATTO, 2009, p. 45).

Nesse prisma, os subalternos podem fomentar uma filosofia crítica e própria a partir da educação, formal e informal, pelo estudo da filosofia da práxis. Esse movimento, consequentemente, trará consciência aos subalternos do movimento e funcionamento da 
sociedade capitalista e neoliberal. Nessa sociedade, a classe burguesa possui finalidades de dominação, pelo convencimento e pela força, e não de conciliação de classes.

\section{REFERÊNCIAS}

ARAÚJO, G. C. de. Federalismo cooperativo e arranjos de desenvolvimento da educação: o atalho silencioso do empresariado para a definição e regulamentação do regime de cooperação. Revista Brasileira de Política e Administração da Educação, v. 28, n. 2, p. 515-531, maio/ago. 2012. Disponível em: http://seer.ufrgs.br/index.php/rbpae/article/view/37419/24160. Acesso em: 20 fev. 2018.

ARAÚJO, G. C. de. Políticas educacionais e estado federativo: conceitos e debates sobre a relação entre municípios, federação e educação no Brasil. Curitiba: Appris, 2013.

ARAÚJO, L.; PINTO, J. M. (org.). Público x privado em tempos de golpe. São Paulo: Fundação Lauro Campos, 2017.

BONAMINO, A. M. C. 0 público e o privado na educação brasileira inovações e tendências a partir dos anos de 1980. Revista brasileira de história da educação, n. 5, p. 253-276, jan./jun. 2003. Disponível em: http://www.vdl.ufc.br/solar/aula_link/lquim/A_a_H/estrutura_pol_gest_educacional/aula_01/ imagens/06/Publico_Privado_Na_Educacao_Brasileira_2.pdf. Acesso em: 8 jan. 2018.

BRASIL. Lei n. 16, de 12 de agosto de 1834. Faz algumas alterações e addições á Constituição Politica do Imperio, nos termos da Lei de 12 de Outubro de 1832. Secretaria de Estado dos Negócios do Império, Rio de Janeiro, 12 ago. 1834. Disponivel em: http://www.planalto.gov.br/ccivil_03/leis/lim/lim16. htm. Acesso em: 1 jul. 2018

BRASIL. Ministério da Administração Federal e Reforma do Estado. Plano Diretor da Reforma do Aparetho do Estado. Aprovado pela Câmara da Reforma do Estado em 21 de setembro de 1995. Brasília, DF: Presidência da República, 1995. Disponível em: http://www.bresserpereira.org.br/documents/mare/ planodiretor/planodiretor.pdf. Acesso em: 1 jul. 2018.

BRASIL. Ministério da Educação. Resolução n. 1, de 30 de maio de 2012. Estabelece Diretrizes Nacionais para a Educação em Direitos Humanos. Diário Oficial da União, Brasília, DF, 31 maio 2012. Disponível em: http://portal.mec.gov.br/dmdocuments/rcp001_12.pdf. Acesso em: 05 de jul. 2018.

BRASIL. Parecer n. 9, de 30 de agosto de 2011. Análise de proposta de fortalecimento e implementação do regime de colaboração mediante arranjos de desenvolvimento da educação. Ministério da Educação. Diário Oficial da União, Brasília, DF, 22 nov. 2011. Disponivel em: http://portal.mec.gov.br/index. php?option=com_docman\&view=download\&alias=8851-pceb009-11-pdf\&category_slug=setembro-2011pdf\&ltemid=30192. Acesso em: 2 mar. 2018.

CARPEAUX, 0. M. A vida de Gramsci. Gramsci e o Brasil, 7 maio 1966. Disponivel em: http://www.artnet. com.br/gramsci/arquiv79.htm. Acesso em: 10 jul. 2017. 
DICIONÁRIO PRIBERAM. Hegemonia. [S. l.: s. n.], [20--2]. Disponivel em: https://www.priberam.pt/dlpo/ hegemonia. Acesso em: 5 jul. 2018.

DIREITA para o social e esquerda para o capital. [S. L.: s. n., 6 maio 2015. 1 video (57 min). Publicado pelo Canal AEPET Nacional. Disponivel em: https://www.youtube.com/watch? $v=W b 35 Z F G v o M s$. Acesso em: 2 jan. 2018.

FLACH, S.; SCHLESENER, A. Educação desinteressada e a análise de políticas educacionais. Revista HISTEDBR, v. 18, n. 3, p. 780-197, jul./set. 2018. Disponivel em: https://www.researchgate.net/publication/328373943_Educacao_desinteressada_e_a_analise_de_politicas_educacionais. Acesso em: 30 abr. 2018.

GOUVEIA, A. B. Financiamento da educação e o município na federação brasileira. Revista Brasileira de Política e Administração da Educação, v. 24, n. 3, p. 437-465, set./dez. 2008. Disponível em: http:// www.seer.ufrgs.br/rbpae/article/viewFile/19267/11190. Acesso em: 30 abr. 2018.

GRAMSCI, A. Cadernos do cárcere volume 1. Introdução ao estudo da filosofia. A filosofia de Benedetto Croce. Edição: Carlos Nelson Coutinho. Rio de Janeiro: Civilização Brasileira, 1999. v. 1.

GRAMSCl, A. Cadernos do cárcere volume 2. 0s intelectuais: o princípio educativo. Jornalismo. 2. ed. Edição: Carlos Nelson Coutinho. Rio de Janeiro: Civilização Brasileira, 2001.

GRAMSCI, A. Cadernos do cárcere volume 3. Maquiavel notas sobre o estado e a política. 7. ed. Edição: Carlos Nelson Coutinho. Rio de Janeiro: Civilização Brasileira, 2016.

GRAMSCl, A. Escritos políticos [1910-1920]. Tradução: Manuel Simões. Lisboa: Seara Nova, 1976. v. 1.

GRUPO DE ESTUDOS E PESQUISA EM POLITICAS EDUCACIONAIS. Apresentação. Campinas: Greppe, [20--?]. Disponivel em: https://greppe.wordpress.com/. Acesso em: 5 abr. 2018.

GRUPPI, L. 0 conceito de hegemonia em Gramsci. Rio de Janeiro: Graal, 1978.

GRUPPI, L. Tudo começou com Maquiavel: as concepções de estado em Marx, Engels, Lênin e Gramsci. Porto Alegre: L\&PM editores, 1986.

IBGE. As fundações privadas e associações sem fins lucrativos no Brasil. Rio de Janeiro: IBGE, 2012.

INSTITUTO NACIONAL DE ESTUDOS E PESQUISAS EDUCACIONAIS ANISIO TEIXEIRA. A Educação no Brasil na década de 90 - 1991-2000. Brasilia, DF: INEP, 2003. Disponivel em: http://portal.inep.gov.br/informacao-da-publicacao/-/asset_publisher/6JYlsGMAMkW1/document/id/486788. Acesso em: 18 jan. 2018.

INSTITUTO NACIONAL DE ESTUDOS E PESQUISAS EDUCACIONAIS ANISIO TEIXEIRA. Censo Escolar da Educação Básica 2011 - Resumo Técnico. Brasilia, DF: INEP, 2012. Disponivel em: http://download.inep.gov. br/educacao_basica/censo_escolar/resumos_tecnicos/resumo_tecnico_censo_educacao_basica_2011.pdf. Acesso em: 18 jan. 2018. 
INSTITUTO NACIONAL DE ESTUDOS E PESQUISAS EDUCACIONAIS ANISIO TEIXEIRA. Resultados e Resumos. Brasilia, DF: INEP, 2018. Disponível em: http://portalinep.gov.br/web/guest/resultados-e-resumos. Acesso em: 18 jan. 2018.

INSTITUTO NACIONAL DE ESTUDOS E PESQUISAS EDUCACIONAIS ANISIO TEIXEIRA. Sinopse estatística da Educação Básica - Censo Escolar 2001. Brasilia, DF: INEP, abr. 2002. Disponivel em: http://portalinep. gov.br/informacao-da-publicacao/-/asset_publisher/6JYlsGMAMkW1/document/id/487773. Acesso em: $८$ jan. 2018.

MARX, K.; ENGELS, F. Feuerbach e História. In: MARX, K.; ENGELS, F. A ideologia Alemã. São Paulo: Boitempo Editorial, 2007. p. 29-77. Disponível em: http://abdet.com.br/site/wp-content/uploads/2014/12/A-Ideologia-Alem\%C3\%A3.pdf. Acesso em: 28 fev. 2018.

NEVES, L. M. W. Direita para o social e esquerda para o capital: intelectuais da nova pedagogia da hegemonia do Brasil. São Paulo: Xamã, 2010.

NEVES, L. M. W. (org.). A nova pedagogia da hegemonia: estratégias do capital para educar o consenso. São Paulo: Xamã, 2005.

SAVIANI, D. Sistema nacional de educação e plano nacional de educação: significado, controvérsias e perspectivas. Campinas, SP: Autores Associados, 2014. (Coleção Polêmicas do Nosso Tempo).

SHEEN, M. R. C. C. A política educacional como momento de hegemonia: notas metodológicas a partir das contribuições de Antônio Gramsci. Revista HISTEDBR, Campinas, SP, n. 25, p. 3-12, mar. 2007.

SIMIONATTO, I. Classes subalternas, lutas de classe e hegemonia: uma abordagem Gramsciana. Rev. katálysis, Florianópolis, v. 12, n. 1, p. 41-49, jun. 2009. Disponivel em: http://www.scielo.br/pdf/rk/ v12n1/06.pdf. Acesso em: 20 jul. 2018.

VIEIRA, S. L. A educação nas constituições brasileiras: texto e contexto. Revista brasileira de Estudos pedagógicos-RBEP, v. 88, n. 219, p. 291-309, maio/ago. 2007.

Endereço para correspondência: Rua Heitor Alves Guimarães, 1040, apto 303, bloco A, Centro, Araucária, Paraná, Brasil; kelly.l.sakata@hotmail.com

Roteiro, Joaçaba, U. 45, p. 1-24, jan./ dez. 2020 | e21332 |E-ISSN 2177-6059 
